Measuring Country Image 
Alexander Buhmann

\section{Measuring \\ Country Image}

Theory, Method, and Effects

Springer VS 
Alexander Buhmann

Oslo, Norway

Dissertation University of Fribourg, Switzerland, 2015

(original title: "The constitution and effects of country images: theory and measurement of a central target construct in international public relations and public diplomacy"), published by Springer Fachmedien Wiesbaden in 2016.

ISBN 978-3-658-15406-6

ISBN 978-3-658-15407-3 (eBook)

DOI 10.1007/978-3-658-15407-3

Library of Congress Control Number: 2016949562

Springer VS

(C) Springer Fachmedien Wiesbaden 2016

This work is subject to copyright. All rights are reserved by the Publisher, whether the whole or part of the material is concerned, specifically the rights of translation, reprinting, reuse of illustrations, recitation, broadcasting, reproduction on microfilms or in any other physical way, and transmission or information storage and retrieval, electronic adaptation, computer software, or by similar or dissimilar methodology now known or hereafter developed.

The use of general descriptive names, registered names, trademarks, service marks, etc. in this publication does not imply, even in the absence of a specific statement, that such names are exempt from the relevant protective laws and regulations and therefore free for general use.

The publisher, the authors and the editors are safe to assume that the advice and information in this book are believed to be true and accurate at the date of publication. Neither the publisher nor the authors or the editors give a warranty, express or implied, with respect to the material contained herein or for any errors or omissions that may have been made.

Printed on acid-free paper

This Springer VS imprint is published by Springer Nature

The registered company is Springer Fachmedien Wiesbaden GmbH

The registered company address is: Abraham-Lincoln-Strasse 46, 65189 Wiesbaden, Germany 


\section{Contents}

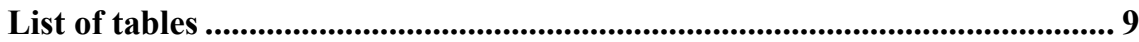

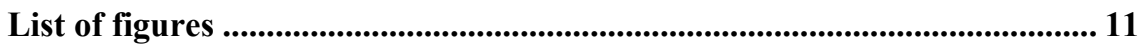

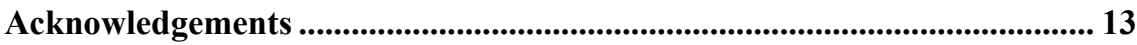

Short summary.......................................................................................................... 15

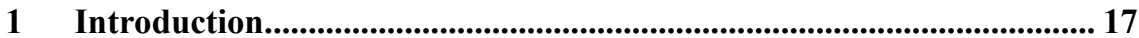

1.1 The country image as a target construct in IPR and PD research ....... 17

1.2 Desiderata: researching the constitution and effects of country

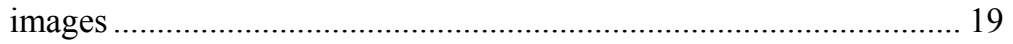

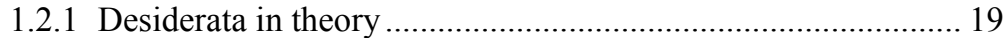

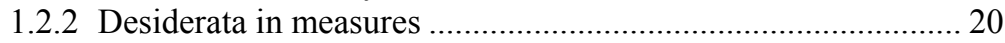

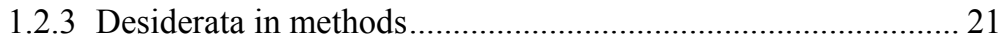

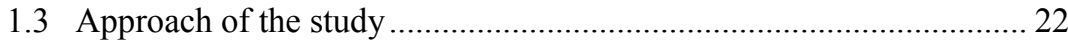

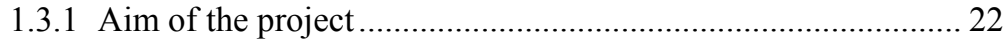

1.3.2 Research questions and study structure ……............................ 23

1.3.3 Epistemological remark ....................................................... 26

2 Towards an integrative model of the country image ............................. 27

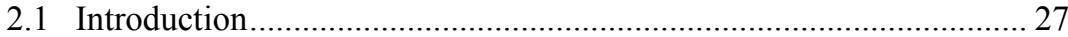

2.2 Central research perspectives .................................................... 29

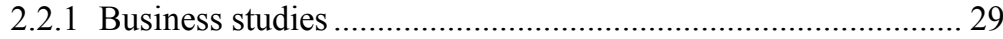

2.2.1.1 Country-of-origin research ...................................... 30

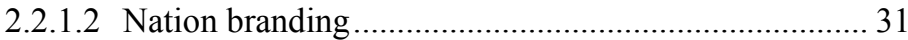

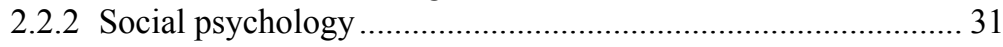

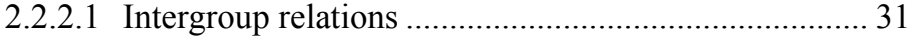

2.2.2.2 Collective identity research ..................................... 32

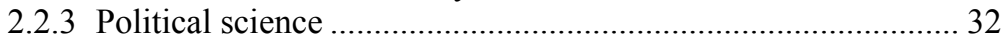

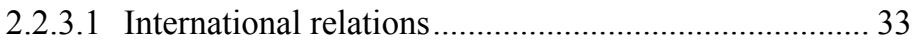

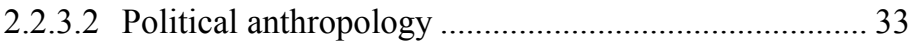

2.2.4 Communication science ....................................................... 34 
2.2.4.1 The general communication science perspective ........ 34

2.2.4.2 The communication management perspective.............. 34

2.3 Applying the perspective of communication management ................. 35

2.3.1 Towards a basic terminological framework .............................. 36

2.3.2 Systemizing concepts of country image, reputation,

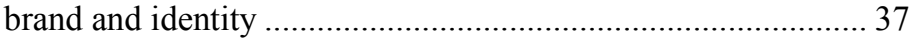

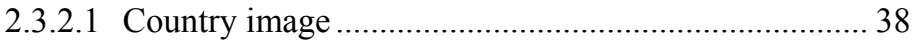

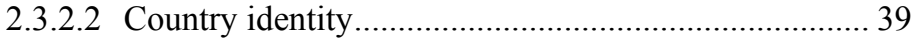

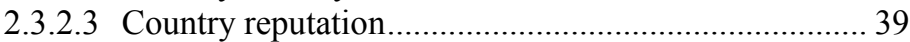

2.3.2.4 Country brand ............................................................ 40

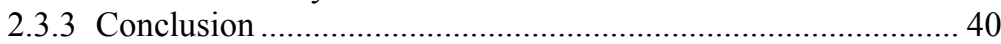

2.4 An integrative model of the country image ......................................... 40

2.4.1 National identity as a basic framework ................................... 41

2.4.2 Country image as attitude ......................................................... 41

2.4.3 Dimensionality of the country image: the 4D Model................ 43

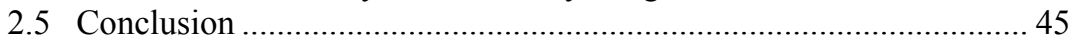

3 A variance-based approach for PR measurement and evaluation ....... 49

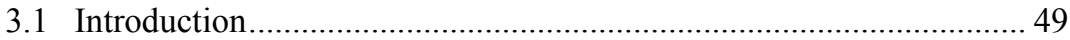

3.2 Basics of PLS-SEM and what it can do for PR research.................... 51

3.2.1 Modeling flexibility and predictive focus ................................ 53

3.2.2 Handling high model complexity.......................................... 54

3.2.3 Sample size requirements .................................................... 55

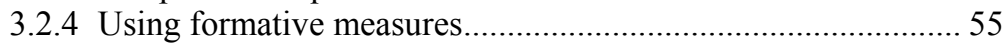

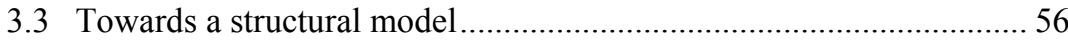

3.3.1 Conceptualizing the multidimensional construct ...................... 57

3.3.2 Trust as an outcome variable .................................................. 58

3.3.3 Trust and behavioral intentions ................................................ 59

3.4 Applying PLS-SEM in public relations evaluation.............................. 60

3.4.1 Developing reflective and formative measurement models ...... 60

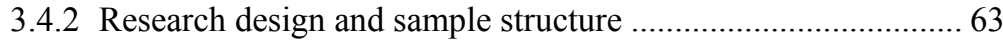

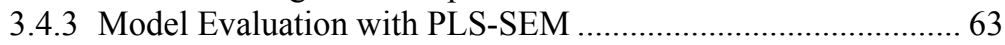

3.4.3.1 Formative measurement model evaluation................... 65

3.4.3.2 Reflective measurement model evaluation................... 69

3.4.3.3 Structural model evaluation.......................................... 71

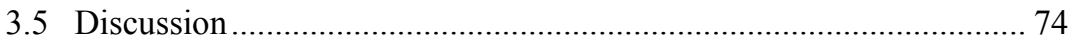

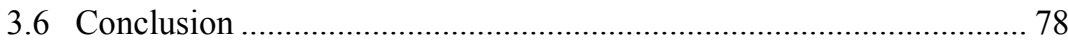




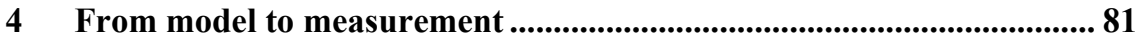

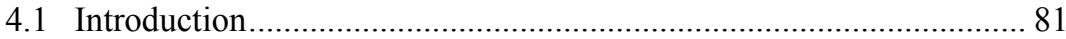

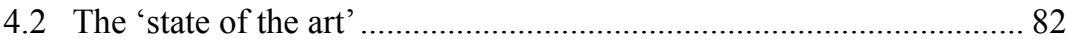

4.2.1 Models and measures in the central research fields .................. 82

4.2.2 A synthesis of central research gaps ........................................ 84

4.3 From model to measurement.............................................................. 85

4.3.1 The 4D Model of the country image ......................................... 85

4.3.2 Defining the epistemic structure of the country image ............. 88

4.3.3 The country image's effect on stakeholder behavior ................ 89

4.3.4 Operationalization of the construct ............................................ 90

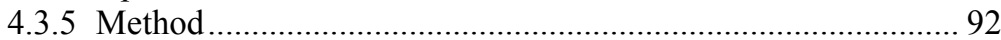

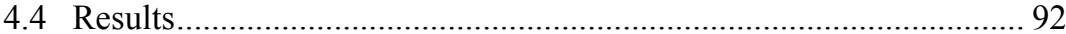

4.4.1 Measurement model.......................................................... 92

4.4.2 Structural relationships ........................................................ 98

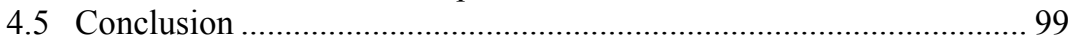

5 The constitution and effects of country image and identity ................ 101

5.1 Research gaps and research questions.............................................. 101

5.2 Towards an integrative framework of country image and identity ... 102

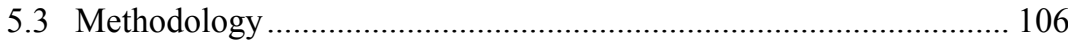

5.3.1 Towards measurement: formative or reflective indicators? .... 106

5.3.2 Operationalization: developing measurement models ............ 107

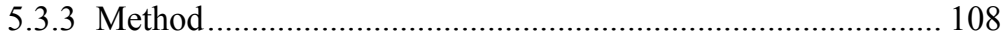

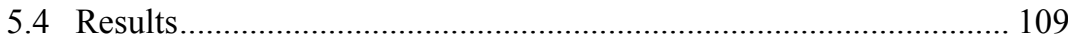

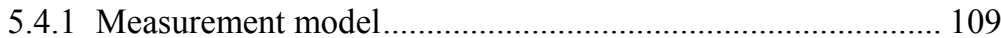

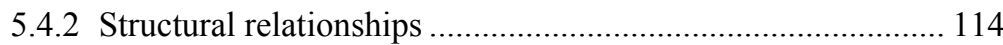

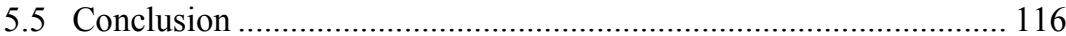

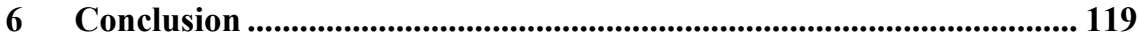

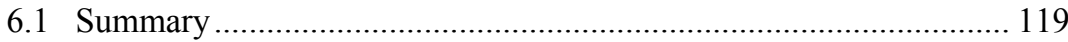

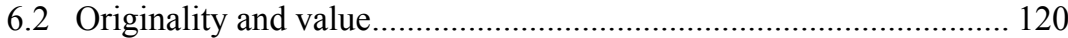

6.2.1 Theoretical advances and implications .................................. 120

6.2.2 Advances and implications in measures ................................ 122

6.2.3 Methodological advances and implications ........................... 122

6.2.4 Advances and implications for IPR and PD practice .............. 123

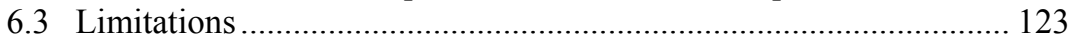

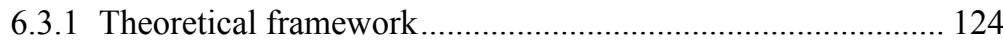

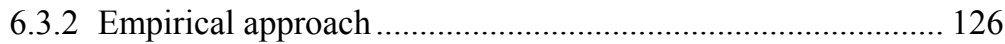

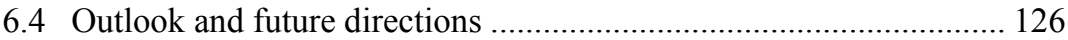


6.4.1 The effects of country images on behavior and the role

6.4.2 Comparative analyses of country images at the level of different groups

6.4.3 Understanding image transfer in crises.......

Endnotes

References. 


\section{List of tables}

Table 1: $\quad$ Comparing key properties between PLS-SEM and CB-SEM ....... 54

Table 2: Indicator weights in the formative models .................................... 65

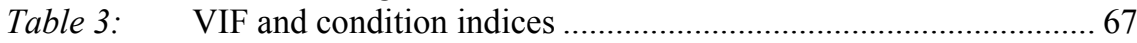

Table 4: $\quad$ Correlations (Pearson) between global measure and

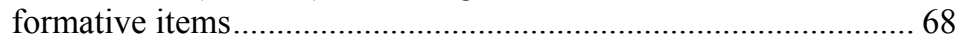

Table 5: Indicator loadings, Chronbach's alpha and AVE in the

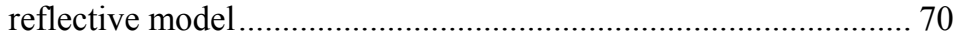

Table 6: $\quad$ Structural model results (path-coefficients and t-values) .............. 72

Table 7: $\quad$ Coefficient of determination for endogenous variables

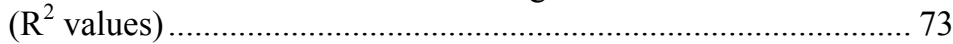

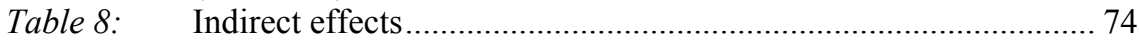

Table 9: $\quad$ Reputation value drivers (ranked highest to lowest) ..................... 76

Table 9: Indicator loadings, Chronbach's alpha, Dillon-Goldstein's rho,

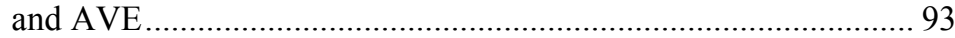

Table 10: Indicator weights of the formative measures............................... 94

Table 11: Variance inflation factor (VIF) of individual country image

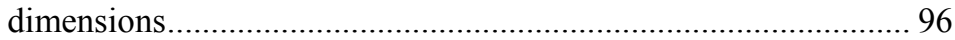

Table 12: Correlation between indicators and summary items...................... 96

Table 13: Indicator loadings, Chronbach's alpha, Dillon-Goldstein's rho,

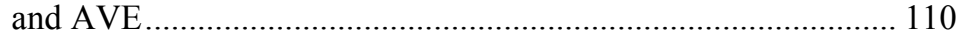

Table 14: Indicator weights of the formative measures................................ 111

Table 15: Variance inflation factor (VIF) of individual dimensions ........... 113

Table 16: Correlation between indicators and summary items.................... 113

Table 17: $\quad$ List of items for measuring reputation ....................................... 155

Table 18: List of items for measuring the country image........................... 157 


\section{List of figures}

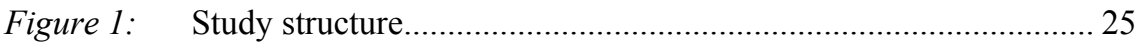

Figure 2: Conceptual relations between organizational identity, communication, and image......................................................... 36

Figure 3: A coordinative framework of country image, reputation,

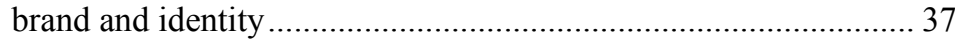

Figure 4: $\quad$ Attributes of a country (based on Smith 1991).............................. 42

Figure 5: $\quad$ The 4D Model of the country image ............................................ 44

Figure 6: Graphic example of SEM (adapted from Roldán, Sánchez-Franco 2012) ................................................................ 52

Figure 7: Structural model of the interrelations between reputational dimensions, organizational trust, and behavioral intentions.......... 60

Figure 8: Two stages of evaluation in PLS-SEM......................................... 64

Figure 9: $\quad$ Structural model results for the stakeholder group of early

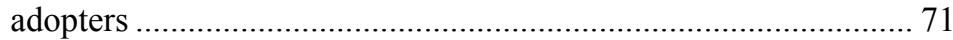

Figure 10: Formative vs. reflective specification of country image

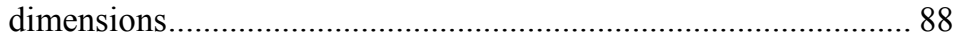

Figure 11: A path model of the constitution and effects of country images ... 90

Figure 12: Epistemic structure and operationalization procedures ................. 91

Figure 13: $\quad$ Path model results - country image and travel behavior ............... 98

Figure 14: Path model results - country identity and behavioral intention... 115

Figure 15: Path model results - country image and behavioral intention ..... 116 


\section{Acknowledgements}

I have many to thank for their contribution, support, and input during the course of this project. Some I would like to specifically express my sincere gratitude to here. First, I want to acknowledge my advisor, Prof. Diana Ingenhoff, for her guidance throughout this process. She was always ready to dedicate her time and energy in many ways, from advancing early ideas and reviewing manuscripts to graciously sharing her social capital during research stays and conferences. Simply put, I could not ask for a better mentor. Also, I am fortunate to have been surrounded by many supportive professors, staff, colleagues, and friends during my time at the University of Fribourg. I am particularly grateful for the support of Prof. emer. Louis Bosshart. It was his dedication, time, and resources that enabled exciting research and lecturing visits at Santa Clara University and Stanford University during the course of this project. Also, I wish to thank Dr. Philipp Bachman and Dr. Christopher Rühl for the uncountable hours they have invested in constructive discussions and for their never-dwindling interest, curiosity, and inspiration - not just for the topics of this dissertation. This project was also supported by the Swiss Association of Communication and Media Research (SACM). I wish to thank the Association for their support and for enabling me to dedicate extra time and attention in the last phase of this dissertation. Finally, and not least, I am deeply grateful for the unconditional support of my wife, Kristin Mc Adam, and my family throughout my doctoral studies. Their love, patience, and encouragement are immeasurable.

A. B.

Bern, June 2016 


\section{Short summary}

The role of country images and knowledge of their constitution and effects is of major interest not only for communication science scholars (especially those in the area of International Public Relations and Public Diplomacy), but also for various research disciplines like Business Studies (esp. International Marketing), Social Psychology, Political Science, as well as for Public Diplomacy practitioners. This book proposes a new model for the measurement of the constitution and effects of country images by combining well-established concepts from national identity theory and attitude theory with a model from reputation management. The model is operationalized and tested in two surveys. Results show how different cognitive and affective dimensions of the image affect each other and the facilitation of behavioral intentions.

Under the conditions of a globalized world and the spread of modern media societies a country's image is becoming more important compared to territory access and raw materials when it comes to the cultural, economic, and political competitiveness of nation-states in the international system (Nye 2004; Gilboa 2008). While research domains, such as marketing and social psychology, have devoted some attention to the constitution and effects of country images from their field perspective, in public relations and public diplomacy research there is no widely accepted model and measurement instrument available. Much like the seminal works of, e.g., Michael Kunczik (1997) or Joseph Nye (2004), many of the studies available in the domain of international public relations and public diplomacy research that touch on the construct of the country image have a rather conceptual or historical focus. Until now it has remained an open question, how the available concepts from other domains may be gainfully combined to derive, specify, and operationalize a comprehensive model of the country image suitable for analyses in international public relations and public diplomacy. Such a specific model and instrument is needed, however, to clarify the constitution of this central target construct in international public relations and public diplomacy and understand how its different dimensions interrelate and affect each other and how they ultimately lead to the facilitation of favorable stakeholder behavior.

The present study combines extant approaches from national identity theory, attitude theory, and reputation management to derive an integrative four- 
dimensional model (4D Model) of the country image as a subjective stakeholder attitude towards a nation and its state, comprising specific beliefs and general feelings in a functional, a normative, an aesthetic and an emotional dimension.

Furthermore, the work advances the debate on methods in the field by introducing variance-based structural equation modeling as a suitable approach to analyzing effects between different latent/emergent country image dimensions and behavioral intentions when handling specific research conditions such as mixed-specified (formative and reflective) constructs, predictive research settings, or relatively large sets of variables and indicators.

Subsequently, both model and method are applied in two sets of empirical studies, which, due to the novelty of the model, serve the development and testing of a new measurement instrument. The latter is developed successively through semi-structured interviews, expert interviews, and item sorting tasks and is then tested and validated by means of three standardized surveys in Switzerland and Germany.

The results retrieved in this study support the proposed model and underscore the value of measuring the country image as a four-factorial construct in international public relations and public diplomacy, comprising both cognitive and affective dimensions. Furthermore, the results a) demonstrate how functional, normative and aesthetic country image dimensions vary in affecting the formation of the affective country image component and b) support the mediating role of the affective component in the country image's effect on stakeholder behavior. 